\title{
Research of Guangdong and Macao Tourism Cooperation Condition based on DEFCA
}

\author{
J.H. Xiao, S.Y. Luo, Y. Yue \\ School of Economics and Management \\ Wuyi University \\ Jiangmen, Guangdong, China
}

\begin{abstract}
With combination of Guangdong and Macao tourism cooperation reality, the evaluation system of tourism cooperation conditions between the 21 prefecture-level cities of Guangdong province and Macao will be established. In allusion to the insufficiency that it is difficult for fuzzy comprehensive evaluation (FCA) to effectively handle quantitative indexes, the concept of Data Envelopment based on Fuzzy Comprehensive Assessment (DEFCA) is proposed, to well overcome those insufficiencies of general FCA model, and find the reason of invalid worse decision-making units in FCA model. In this paper, DEFCA helps to obtain the comprehensive assessment results and improvement directions of tourism cooperation conditions between the 21 prefecture-level cities of Guangdong province and Macao, for further putting forward suggestions of future tourism cooperation between Guangdong and Macao.
\end{abstract}

Keywords-cooperation conditions; evaluation system; FCA; DEA; DEFCA

\section{INTRODUCTION}

With the successive tourism cooperation between Nansha of Guangzhou, Hengqin of Zhuhai, Shenzhen, Zhongshan and Macao and achieving phased results, those remaining cities and counties in Guangdong province also expect to forward tourism cooperation with Macao. However, regional tourism cooperation is an economic fusion with an extensive coverage, and only scientific and rigorous arguments can clarify whether the regional tourism cooperation conditions are sufficient, and whether the conditions can support and guarantee smooth implementation of regional tourism cooperation activities. Therefore, reference of pertinent literature and combination of tourism cooperation reality between Guangdong and Macao can help to establish tourism cooperation conditions evaluation system. The fuzzy comprehensive evaluation model DEFCA based on data envelopment analysis is introduced in , of which DEA is applied to calculate the combined efficiency of quantification indexes in this system and then fuzzification treatment, FCA calculate comprehensive assessment results of quantitative indexes' overall efficiency to fuzz up and quantification indexes. Finally, tourism cooperation suggestions between Guangdong and Macao will be put forward upon the evaluation results.

\section{TOURISM COOPERATION CONDITIONS EVALUATION SYSTEM BETWEEN GUANGDONG AND MACAO}

There are many factors of influencing regional tourism cooperation conditions, and Chinese and overseas scholars have made a large number of research on this: Katarzyna [1], et al divide the influencing factors into two categories, exogenous factors and endogenous factors, and researched on the tourism cooperation of mountainous regional tourist area in the south of Poland by the subdivision into economy, society, culture, population, law, politics, space and other relevant factors; Li Fei [2] has put forward economic level, consumption power of residents, tourism development level, the similarity and complementarity of tourism resources, spatial association and other relevant factors, and has analyzed the tourism cooperation conditions of the six circum-Bohai-Sea cities of Liaoning; Duan Shengkui [3] et al have proposed the factors of influencing regional tourism cooperation from sex aspects of economy, resource, culture, policy, market and location on a basis of systematicness, relatedness, differentiation and scale, and also have structured regional tourism cooperation conditions evaluation system for further empirical research on north of Jiangsu; Zhu Cuilan [4] et al have structured a tourism cooperation system evaluation pointer system that involves 17 factors for the areas of Xiamen, Zhangzhou and Quanzhou from the four aspects of tourism subject subsystem, tourism object subsystem, tourism medium subsystem and tourist environment subsystem; Yang Lei [5] et al have put forward a regional tourism cooperation performance evaluation pointer system that involves 5 aspects and 20 factors, including regional tourism resource cooperative development, regional tourism transportation network construction, regional tourism market cooperative development, regional tourism image building, regional tourism cooperation policy and management and so on. All these can be applied for comprehensive assessment research towards the tourism cooperation performance in Shenyang economic region, but research of the tourism cooperation study aiming at Guangdong and Macao, these two specific areas , is short.

Hence, predecessors' researches and the tourism cooperation reality between Guangdong and Macao will be summarized in this paper, and the tourism cooperation conditions between Guangdong and Macao will be resolved into development status of tourist industry, tourism cooperation basis, tourism exchange activity, total 3 layers and 15 indexes, which are divided in detail as Fig.1 shows. 
TABLE I. TOURISM COOPERATION CONDITIONS EVALUATION SYSTEM BETWEEN GUANGDONG AND MACAO.

\begin{tabular}{|c|c|c|}
\hline $\begin{array}{l}\text { Target } \\
\text { Level }\end{array}$ & Project Level (P) & Factor Level (F) \\
\hline \multirow{15}{*}{$\begin{array}{l}\text { Tourism } \\
\text { Cooperation } \\
\text { conditions } \\
\text { evaluation } \\
\text { system }\end{array}$} & \multirow{5}{*}{$\begin{array}{l}\text { Tourism development } \\
\text { situation } \mathrm{P}_{1}\end{array}$} & Total income of tourism $\mathrm{F}_{11}$ \\
\hline & & Quantity of tourists with entry for overnight $F_{12}$ \\
\hline & & Quantity of travel agenciesF $F_{13}$ \\
\hline & & Quantity of hotels and restaurants $F_{14}$ \\
\hline & & Quantity of employees $\mathrm{F}_{15}$ \\
\hline & \multirow{6}{*}{$\begin{array}{l}\text { Tourism cooperation ba- } \\
\text { sisP }_{2}\end{array}$} & Resource condition $\mathrm{F}_{21}$ \\
\hline & & Locational condition $\mathrm{F}_{22}$ \\
\hline & & Infrastructure condition $\mathrm{F}_{23}$ \\
\hline & & Policy conditionF $F_{24}$ \\
\hline & & Market condition $\mathrm{F}_{25}$ \\
\hline & & Culture condition $\mathrm{F}_{26}$ \\
\hline & \multirow{4}{*}{$\begin{array}{l}\text { Tourism exchange activity } \\
\mathrm{P}_{3}\end{array}$} & Inter-governmental exchange and cooperation $\mathrm{F}_{31}$ \\
\hline & & $\begin{array}{l}\text { Cooperation between tourism industry associations } \\
\mathrm{F}_{32}\end{array}$ \\
\hline & & Cooperation between tourist enterprises $\mathrm{F}_{33}$ \\
\hline & & Non-governmental exchangeF $F_{34}$ \\
\hline
\end{tabular}

\section{DEFCA MODEL}

\section{A. Proposition of DEFCA Model}

Fuzzy Comprehensive Assessment (FCA) can nicely solve the fuzzy qualitative index problem in comprehensive evaluation, and has an obvious superiority in handling qualitative index. However, it has defects in handling quantitative index, and present great subjective dependency.

Data Envelopment Analysis (DEA) can nicely handle those quantitative evaluation indexes with input-output economic signification in evaluation system, and put forward suggestions for improvement on a basis of projection theorem. But about its defects, it cannot handle qualitative index well, and present a strong dependency on objective data.

From Figure 1, we can see that the five subordinate indexes of tourism development P1 can be indicated with relevant statistical data, while the ten subordinate indexes of tourism cooperation basis P2 and tourism exchange activity P3 cannot be quantized. The relevant membership can only be acquired through the fuzzy conversion towards subjective factors by specialists. Both qualitative index and quantitative index exist are in the tourism cooperation conditions evaluation system between Guangdong and Macao. For the evaluation system of such tourism cooperation conditions and subjectivity reduction of specialists' rating, this paper puts forward Data Envelopment based on Fuzzy Comprehensive Assessment (DEFCA) to evaluate this system with synthesized merits of FCA and DEA[6].

\section{B. DEFCA Modeling}

Fundamental of DEFCA model: DEA can calculate the overall efficiency of quantitative indexes in the evaluation system and fuzz up it; while FCA can calculate the overall efficiency of fuzzification and the membership of qualitative index in this evaluation system, and the final evaluation results of decision-making unit can be acquired upon maximum membership principle.

DEFCA modeling steps:

(1) DEA calculation and fuzzification treatment of quantitative index. $\mathrm{n}$ decision-making units ( $\mathrm{n}$ as cities) will be set up, and each decision-making unit includes $m$ kinds of inputs and $s$ kinds of outputs. $m+s$ means the quantity of quantitative indexes in the system, and these quantitative indexes satisfy input-output economic significance. In this paper, constant returns to scale model (CRS) and variable return to scale model (VRS) are mainly applied to strive for overall efficiency, pure technical efficiency and scale efficiency of decision-making units.

If the overall efficiency of evaluation system is valid, overall efficiency can be used to represent the indexes in this system. However, combined efficiency has no the evaluation function of "excellent, medium and general", and no membership formation required in fuzzy comprehensive assessment, so isosceles triangle membership function is used in this paper to get the membership of quantitative index in this system, $B_{j}=\left(b_{j 1}, b_{j 2}, \cdots, b_{j i}, \cdots, b_{j p}\right)$, and $p$ is the quantity of quantitative indexes in divisor layer within this system.

(2) FCA calculation of qualitative index.

(1)Analytic hierarchy process (AHP) is used to obtain the qualitative index weight in divisor layer within the tourism cooperation conditions evaluation system between Guangdong and Macao, recorded as $A_{j}=\left(a_{j 1}, a_{j 2}, \cdots, a_{j q}\right)$, $j=1,2, \cdots, p$, and $q$ is the quantity of qualitative evaluation indexes in this system.

(2)Establishing evaluation and endowing relevant scoring criteria. Semantic difference measurement table is used to divide remark collection $V=\left(v_{1}, v_{2}, \cdots, v_{k}\right)$ into three grades, "excellent”, "medium” and "general”, and $\mathrm{k}$ is the quantity of fuzzy comprehensive evaluation grades. Here $\mathrm{k}=3$.

(3)Fuzzy comprehensive evaluation: the acquired membership of qualitative pointer of No. ${ }^{j}$ decision-making unit by FCA $B_{j}=A_{j} R_{j}$, and $R_{j}$ is comprehensive evaluation matrix.

(3) Fuzzification overall efficiency of quantitative index and fuzzy comprehensive evaluation for FCA membership of qualitative index. 
(1) Project layer index weight of tourism cooperation conditions evaluation system between Guangdong and Macao, recorded as $A=\left(a_{1}, a_{2}, \cdots, a_{f}\right)$, and $\mathrm{f}$ is the quantity of project layer indexes;

(2) Comprehensive evaluation matrix of quantitative and qualitative indexes is $R=\left(B_{1}, B_{2}, \cdots, B_{f}\right)^{T}$;

(3) On a basis of the maximum membership principle, the maximal membership

in $B=A R=\left(a_{1}, a_{2}, \cdots, a_{f}\right)\left(B_{1}, B_{2}, \cdots, B_{f}\right)^{T}$ will be selected as the comprehensive evaluation results of this decision-making unit.

\section{THE APPLICATION OF DEFCA MODEL IN THE TOURISM COOPERATION CONDITIONS EVALUATION BETWEEN GUANGDONG AND MACAO}

First of all, in allusion to the non-quantitative index in tourism cooperation conditions evaluation system between Guangdong and Macao, F11 and F12 shall be input as decision-making units, and F13, F14 and F15 shall be output as decision-making units. The DEA calculation results upon the data published in 2013 Guangdong Province Tourism Statistics Yearbook shows the relative efficiency of tourism development of the 21 cities of Guangdong. Then the overall efficiency fuzzification membership can be acquired with remark collection $\mathrm{V}=$ (excellent, medium and bad) and isosceles triangle membership function, and the results are shown as Table 1 Tourism Development Situation.

TABLE II. QUANTITATIVE AND QUALITATIVE INDEX PROCESSING RESULTS.

\begin{tabular}{|c|c|c|c|c|c|c|c|c|}
\hline \multirow[t]{3}{*}{ City } & \multicolumn{5}{|c|}{ DEA calculation results } & \multicolumn{3}{|c|}{ Tourism development (P1) } \\
\hline & \multirow{2}{*}{$\begin{array}{c}\text { Pure } \\
\text { technical } \\
\text { effi- } \\
\text { ciency }\end{array}$} & \multirow{2}{*}{\multicolumn{2}{|c|}{$\begin{array}{c}\text { Scale } \\
\text { effi- } \\
\text { ciency }\end{array}$}} & \multirow{2}{*}{$\begin{array}{c}\text { Overall } \\
\text { effi- } \\
\text { ciency }\end{array}$} & \multirow{2}{*}{$\begin{array}{c}\text { Re- } \\
\text { turns } \\
\text { to } \\
\text { scale }\end{array}$} & \multicolumn{3}{|c|}{$\begin{array}{l}\text { Overall efficiency Fuzzifica- } \\
\text { tion membership B1 }\end{array}$} \\
\hline & & & & & & $\begin{array}{c}\text { Excel- } \\
\text { lent }\end{array}$ & & General \\
\hline $\begin{array}{l}\text { Guang- } \\
\text { zhou }\end{array}$ & 1.000 & \multicolumn{2}{|c|}{1.000} & 1.000 & - & 1.000 & & 0.000 \\
\hline Shenzhen & 1.000 & \multicolumn{2}{|c|}{1.000} & 1.000 & - & 1.000 & 0.000 & 0.000 \\
\hline Zhuhai & 0.617 & \multicolumn{2}{|c|}{0.984} & 0.607 & irs & 0.214 & 0.786 & 0.000 \\
\hline Shantou & 0.454 & \multicolumn{2}{|c|}{1.000} & 0.454 & - & 0.000 & 0.908 & 0.092 \\
\hline Foshan & 1.000 & \multicolumn{2}{|c|}{0.964} & 0.964 & drs & 0.928 & 0.072 & 0.000 \\
\hline Shaoguan & 0.384 & & 67 & 0.371 & irs & 0.000 & & 0.258 \\
\hline Heyuan & 0.464 & & & 0.462 & irs & 0.000 & & 0.760 \\
\hline Meizhou & 0.891 & & 99 & 0.889 & drs & 0.778 & & 0.000 \\
\hline Huizhou & 0.870 & & & 0.789 & irs & 0.578 & & 0.000 \\
\hline Shanwei & 0.924 & & 41 & 0.500 & irs & 0.000 & & 0.000 \\
\hline Dongguan & 1.000 & & & 1.000 & - & 1.000 & & 0.000 \\
\hline $\begin{array}{c}\text { Zhong- } \\
\text { shan }\end{array}$ & 0.731 & & 94 & 0.727 & irs & 0.454 & & 0.000 \\
\hline Jiangmen & 1.000 & & & 1.000 & - & 1.000 & & 0.000 \\
\hline Yangjiang & 0.999 & & 21 & 0.920 & irs & 0.840 & & 0.000 \\
\hline Zhanjiang & 0.396 & & 376 & 0.347 & irs & 0.000 & & 0.306 \\
\hline Maoming & 0.792 & & 765 & 0.606 & irs & 0.212 & & 0.000 \\
\hline Zhaoqing & 0.837 & & 388 & 0.743 & irs & 0.486 & & 0.000 \\
\hline Qingyuan & 0.514 & & & 0.510 & drs & 0.020 & & 0.000 \\
\hline Chaozhou & 1.000 & & 00 & 1.000 & - & 1.000 & & 0.000 \\
\hline Jieyang & 0.719 & & & 0.527 & irs & 0.054 & & 0.000 \\
\hline Yunfu & 1.000 & & 00 & 1.000 & - & 1.000 & & 0.000 \\
\hline Touri & n coopera & 1 & $\operatorname{sis}(\mathbf{P}$ & & Tour & 1 exchan & & y (P3) \\
\hline Fuzz & cation me & 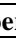 & ip B & & Fuz & cation $\mathrm{m}$ & lbe & ip B3 \\
\hline Excellent & Medi & & Ex & llent & Medium & Excell & & Medium \\
\hline 0.6794 & 0.27 & & & & 0.2785 & 0.679 & & 0.2785 \\
\hline 0.6090 & 0.34 & & & & 0.3489 & 0.60 & & 0.3489 \\
\hline 0.5833 & 0.32 & & & & 0.3263 & 0.58 & & 0.3263 \\
\hline 0.2200 & 0.46 & & & & 0.4629 & 0.22 & & 0.4629 \\
\hline 0.5101 & 0.38 & & & 101 & 0.3823 & 0.510 & & 0.3823 \\
\hline 0.4000 & 0.37 & & & 000 & 0.3723 & 0.400 & & 0.3723 \\
\hline 0.2125 & 0.39 & & & 125 & 0.3967 & 0.212 & & 0.3967 \\
\hline 0.2579 & 0.32 & & & 579 & 0.3206 & 0.25 & & 0.3206 \\
\hline 0.4345 & 0.33 & & & 345 & 0.3358 & 0.43 & & 0.3358 \\
\hline 0.2119 & 0.46 & & & 119 & 0.4609 & 0.21 & & 0.4609 \\
\hline 0.4264 & 0.47 & & & 264 & 0.4736 & 0.426 & & 0.4736 \\
\hline 0.5336 & 0.36 & & & 336 & 0.3651 & 0.53 & & 0.3651 \\
\hline 0.5738 & 0.31 & & & 738 & 0.3162 & 0.573 & & 0.3162 \\
\hline 0.2761 & 0.47 & & & 761 & 0.4767 & 0.27( & & 0.4767 \\
\hline 0.2099 & 0.51 & & & 99 & 0.5107 & 0.20 & & 0.5107 \\
\hline 0.1741 & 0.41 & & & & 0.4150 & 0.17 & & 0.4150 \\
\hline
\end{tabular}




\begin{tabular}{|l|l|l|l|l|l|}
\hline 0.3799 & 0.4622 & 0.3799 & 0.4622 & 0.3799 & 0.4622 \\
\hline 0.3724 & 0.4168 & 0.3724 & 0.4168 & 0.3724 & 0.4168 \\
\hline 0.2157 & 0.3848 & 0.2157 & 0.3848 & 0.2157 & 0.3848 \\
\hline 0.1779 & 0.4130 & 0.1779 & 0.4130 & 0.1779 & 0.4130 \\
\hline 0.2756 & 0.3465 & 0.2756 & 0.3465 & 0.2756 & 0.3465 \\
\hline
\end{tabular}

Note: returns to scale: “_” means constant returns to scale, “irs” means increasing returns to scale, and “drs” means decreasing returns to scale.

Secondly, the evaluation perforce in tourism cooperation basis and tourism exchange activity of the 21 cities is worked out with FCA, and the results are shown as table 1 Tourism Cooperation Basis (P2) and Tourism Exchange Activity (P3).

Finally, DEFCA comprehensive evaluation of the 21 cities in Guangdong Province. In allusion to the quantitative indexes of tourism cooperation conditions evaluation system between Guangdong and Macao, the synthesis of a large number of document literatures can help to obtain the three project layer pointer weight of tourism development situation
(P1), tourism cooperation basis (P2), tourism exchange activity (P3) in the tourism cooperation conditions evaluation system, $\left(a_{1}, a_{2}, a_{3}\right)=(0.143,0.714,0.143)$;a new membership matrix combined by quantitative index fuzzification membership B1, qualitative index fuzzification membership B2and B3, R=(B1,B2,B3) and the tourism cooperation comprehensive assessment performance between the 21 cities of Guangdong and Macao upon maximum membership principle, and the results are in table 2.

TABLE III. COMPREHENSIVE EVALUATION RESULTS OF TOURISM COOPERATION BETWEEN THE 21 CITIES OF GUANGDONG AND MACAO.

\begin{tabular}{|c|c|c|c|c|c|c|c|c|c|}
\hline \multirow[t]{2}{*}{ City } & \multicolumn{3}{|c|}{$\begin{array}{l}\text { DEFCA comprehensive } \\
\text { evaluation membership }\end{array}$} & \multirow{2}{*}{$\begin{array}{l}\text { Evaluation } \\
\text { result }\end{array}$} & \multirow[t]{2}{*}{ City } & \multicolumn{3}{|c|}{$\begin{array}{l}\text { DEFCA comprehensive } \\
\text { evaluation membership }\end{array}$} & \multirow{2}{*}{$\begin{array}{l}\text { Evaluation } \\
\text { result }\end{array}$} \\
\hline & Excellent & Medium & Bad & & & Excellent & Medium & Bad & \\
\hline Guangzhou & 0.7220 & 0.2417 & 0.0363 & Excellent & Zhongshan & 0.5208 & 0.4006 & 0.0785 & Excellent \\
\hline Shenzhen & 0.6717 & 0.2920 & 0.0363 & Excellent & Jiangmen & 0.6276 & 0.2876 & 0.0731 & Excellent \\
\hline Zhuhai & 0.5410 & 0.3866 & 0.0725 & Excellent & Yangjiang & 0.3578 & 0.4262 & 0.2160 & Medium \\
\hline Shantou & 0.2000 & 0.5248 & 0.2752 & Medium & Zhanjiang & 0.1904 & 0.5251 & 0.2845 & Medium \\
\hline Foshan & 0.5422 & 0.3380 & 0.1198 & Excellent & Maoming & 0.1664 & 0.4368 & 0.3967 & Medium \\
\hline Shaoguan & 0.3521 & 0.4204 & 0.2159 & Medium & Zhaoqing & 0.4052 & 0.4574 & 0.1294 & Medium \\
\hline Heyuan & 0.1598 & 0.4432 & 0.4948 & General & Qingyuan & 0.3036 & 0.4861 & 0.2104 & Medium \\
\hline Meizhou & 0.3308 & 0.3177 & 0.3515 & General & Chaozhou & 0.3365 & 0.3240 & 0.3394 & General \\
\hline Huizhou & 0.4419 & 0.3683 & 0.1898 & Excellent & Jieyang & 0.1557 & 0.4698 & 0.3802 & Medium \\
\hline Shanwei & 0.1706 & 0.5155 & 0.3023 & Medium & Yunfu & 0.3631 & 0.2886 & 0.3366 & Excellent \\
\hline Dongguan & 0.5008 & 0.4026 & 0.0966 & Excellent & & & & & \\
\hline
\end{tabular}

V. TOURISM COOPERATION EVALUATION RESULT ANALYSIS

From DEFCA comprehensive evaluation results of Guangdong provincial 21 cities and Macao, following three conclusions can be available.

(1) The tourism cooperation conditions comprehensive evaluation results between the 9 cities of Guangzhou, Shenzhen, Zhuhai, Foshan, Huizhou, Dongguan, Zhongshan and Jiangmen with Macao are "Excellent", which means that the tourism cooperation between these 9 cities and Macao has a superior condition; the tourism cooperation conditions comprehensive evaluation results between the 9 cities of Shantou, Shaoguan, Shanwei, Yangjiang, Zhanjiang, Maoming, Zhaoqing, Qingyuan and Jieyang with Macao are "Medium”, because the scores of these 9 cities in tourism cooperation basic conditions and tourism exchange activity are ordinary, and that the tourism efficiency of all these cities fails to reach DEA efficiency. The tourism cooperation conditions comprehensive evaluation results between the 3 cities of Heyuan, Meizhou and Chaozhou with Macao are "General", because these 3 cities have a weaker tourism resource, location, policy and market condition that other cities, and less tourism exchange activity with Macao.

(2) DEA is valid in Guangzhou, Shenzhen, Dongguan, Jiangmen, Yunfu, Shantou and Chaozhou, but keeps constant returns to scale, which means that innovation is necessary in tourism cooperation between these 7 cities and Macao, or it is difficult to bring any new breakthrough in tourist industry.
DEA of other cities is invalid, which means the resource use efficiency of these cities is quite low. Among these cities, Zhuhai, Shaoguan, Heyuan, Huizhou, Shanwei, Zhongshan, Yangjiang, Zhanjiang, Maoming, Zhaoqing and Jieyang present increasing return to scale, which means tourism resource investments are insufficient, and proper increase of tourism resource investments can help to acquire a higher proportion of outputs; while the 3 three cities of Foshan, Meizhou and Qingyuan present decreasing return to scale, which means the tourism resource investments of these 3 cities are superfluous, so the investments shall be reasonably optimized and idle resource shall be reduced. In the 14 cities of DEA nullity, only pure technical efficiency of Foshan is valid, and pure technical efficiencies of other cities are all invalid. These cities shall actively structure intelligent tourism informatization platforms and other tourism cooperation platforms for Macao and peripheral areas, to absorb excellent managerial experience and techniques for reference and structure intelligent tourism informatization platforms for promoting pure technical efficiency. The scale efficiency of the 14 cities with invalid DEA also is invalid. Therefore, these 14 cities shall adjust existing usage mode of tourism resources, and enhance effective availability of resources.

(3) Above analysis will have a significant promotion effect on accelerating tourism cooperation progress between Guangdong and Macao by perfecting tourism infrastructure of all cities in Guangdong, increasing intelligent tourism informatization construction, constructing communication platforms in virtue of Guangdong-Hong Kong-Macao Bridge 
and Guangdong-Hong Kong-Macao Free Trade Area, and structuring resource optimization, cash flow, technical exchange, personnel support and other systems between Guangdong and Macao. Heyuan, Meizhou and Chaozhou with "General" tourism cooperation conditions in the east of Guangdong shall try to compose Chaozhou-Hakka Culture Tourist Area with alliance of Shantou, Jieyang and Shanwei, and promote Chaozhou-Hakka cultural tourism resources combinations with links of Chaozhou-Shantou cultures and Hakka culture.

\section{REFERENCES}

[1] Katarzyna, Czernek, DETERMINANTS OF COOPERATION IN A TOU-RIST REGION. Annals of Tourism Research, 40,pp. 83104,2013.

[2] Li Fei, Analysis of Tourism Cooperation Conditions for SixCities of Liaon-ing in Bohai Rim. Journal of Shenyang Normal University ( Natural Scienc-e), 01,pp.112-115,2008.

[3] Duan Shengkui, Research on the Evaluation on Cooperative Conditions for Regional Tourism-Taking Northern Jiangsu as an Example. Journal of C-hongqing Technology and Business University (Natural Science Edition),11,pp.104-109,2012.

[4] Zhu Cuilan, Hou Zhiqiang, A Study on the Evolution of Regional Tourism Cooperating System-XiaZhangQuan area as an example. Tourism Forum, 05,pp.56-61,2013,

[5] Yang Lei, Ma Shuai, Dai Weidong, Performance Evaluation of Regional T-ourism Cooperation in Shen Yang Economic Zone. Chinese market,19,pp.94-96,2012.

[6] Liu Shun, Du Shuxin, Fuzzy Comprehensive Evaluation Based on Data En-velopment Analysis. Fuzzy Systems and M athematics,02,pp.93-98,2010. 